\title{
Mechanics and pyrolysis analyses of rotation welding with pretreated wood dowels
}

\author{
Xudong Zhu ${ }^{1,2} \cdot$ Ying Gao $^{1,2} \cdot$ Songlin $\mathrm{Yi}^{1,2} \cdot$ Chun $\mathrm{Ni}^{3} \cdot$ Jirong Zhang ${ }^{1,2}$. \\ Xiangya Luo ${ }^{1,2}$
}

Received: 12 November 2016 / Accepted: 30 January 2017 / Published online: 14 March 2017

(C) The Japan Wood Research Society 2017

\begin{abstract}
This study examined the mechanics and pyrolysis analyses of rotation welding with treated dowels. Test results indicated that welding specimens with dowels immersed in $\mathrm{CuCl}_{2}$ solution exhibited higher pullout resistance than untreated specimens. Scanning electron microscopy was used to observe and analyze the welding interface. Wood dowels immersed in $\mathrm{CuCl}_{2}$ solution provided more flowing molten polymer to obtain better connection than untreated wood dowels. Based on the chemical analyses of X-ray photoelectron spectroscopy, and thermogravimetric analyses, the hydrolysis of cellulose and hemicellulose was detected after immersion of the dowels in a $\mathrm{CuCl}_{2}$ solution. Pyrolysis of cellulose, hemicellulose and lignin occurred during the welding process. The hydrolysis of
\end{abstract}

Ying Gao

gaoying@bjfu.edu.cn

Xudong Zhu

zhuxudong5008@bjfu.edu.cn

Songlin Yi

ysonglin@126.com

Chun Ni

tonichun123@gmail.com

Jirong Zhang

zhangjirong@bjfu.edu.cn

Xiangya Luo

toluoxiangya@gmail.com

1 Beijing Key Laboratory of Wood Science and Engineering, Beijing Forestry University, Beijing 100083,

People's Republic of China

2 MOE Key Laboratory of Wooden Material Science and Application, Beijing Forestry University, Beijing 100083, People's Republic of China

3 FPInnovations, Vancouver, Province of British Columbia, Canada cellulose and hemicellulose may promote the pyrolysis and efficient connection of wood components during the welding process.

Keywords Rotation welding · Treated dowels · Hydrolysis · Pyrolysis

\section{Introduction}

Welding technology is extensively applied in the fields of metals and plastics. This environmentally friendly way of connecting materials creates a new welding interface layer with the production of friction heating. During the generation of friction, thermoplastic materials are softened and fused and can be solidified once the friction is stopped. The main components of wood are cellulose, hemicellulose and lignin as a type of natural polymer material. In general, when wood is heated, the cellulose remains relatively stable, the hemicellulose generates thermal pyrolysis, and the lignin becomes softened [1,2].

Four types welding methods are typically used: linear welding, orbital friction welding, circular welding, and rotation welding. These methods differ in velocity and force. In linear and orbital friction welding, the velocity and frictional force is a sinusoidal wave caused by linear oscillatory and elliptical movement, respectively, during welding. For circular and rotation welding, the velocity and frictional force are constant and caused by a circular and rotation movement [3]. Linear welding and rotation welding have been well studied. Linear welding occurs with high-speed linear motion between the surfaces of two wood blocks. In this method, the welding pressure, amplitude, frequency, holding pressure, and time are the main parameters affecting welding efficiency. In contrast, wood dowel 
welding with lignin softening and degradation is caused by the increase in temperature resulting from the friction generated by the high-speed rotation between the wood dowel and the substrate hole [4-7].

The theoretical temperature may reach $456.65 \mathrm{~K}$ during wood dowel welding in 0.9-1.2 $\mathrm{s}$ due to friction [8]. Then, the temperature reduces to $413.15 \mathrm{~K}$ without additional interface materials. The well-distributed molten polymer generated by the increased temperature affects the water resistance. The wood dowel welding joints perform well with increased water resistance. No obvious delamination appeared after 8 months in a humid environment because of the special wood dowel welding connection [9].

The interface materials are composed primarily of the wood dowels [10] and the welding interface is influenced by the rotation and insertion speeds. A good wood-dowel welding interface requires a fine balance between rotation and insertion speeds and these may differ for different materials. While for European beech (Fagus sylvatica) the optimum rotation speed of the dowels was of 1200 to $1600 \mathrm{rpm}$ using dowels of $10 \mathrm{~mm}$ in diameter [11], the ideal speed for Norway spruce substrate was $1000 \mathrm{rpm}$ with beech dowels of $12 \mathrm{~mm}$ in diameter [12]. If the rotation speed is excessive, it will cause charring in the interface. At high rotation speed, a constant insertion speed may induce better welding properties than an accelerated speed [13]. A constant insertion speed of $25 \mathrm{~mm} / \mathrm{s}$ gave the best results for sugar maple and $16.7 \mathrm{~mm} / \mathrm{s}$ was the best for yellow birch [14], with sugar maple showing better overall welding properties.

According to several studies, welding properties could be significantly improved using smaller pre-drilled holes, dry wood dowels and increasing the contact area with nonvertical insertion methods. The smaller pre-drilled holes may increase the lateral pressure between the wood dowels and the pre-drilled holes. The wood dowels may provide more materials for the interface. Dry wood dowels after welding may absorb water from the environment. Wood dowels in a state of inflation may increase the bonding strength [11, 14-17]. It was found that native extractives of some special wood species could improve the water resistance [18-20]. Placencia and Pizzi compared welded joints with and without additives and found that welded joints with natural additives (rosin and lignin) showed improved water resistance [21, 22]. Water extracts of welded beech and welded spruce were analyzed after hydrolysis of welded materials and amounts of lignin, mono-oligosaccharides, acetic acid, vanillin, furfural, 5 hydroxymethylfurfural, and syringaldehyde were measured [23].

Chemical changes occurred in the wood components including the depolymerization and pyrolysis of cellulose, hemicellulose and lignin during welding. According to the research of Karl-Christian, acid-catalyzed cleavage of carbohydrates and the formation of formaldehyde, furfural, and other aldehydes occurred with the elevated temperature. In addition, lignin was cleaved and began auto-condensation [24]. With the changes in the wood components, the free phenolic hydroxyl groups increased and formed the hydrogen bonds with the cellulose to strengthen the stability of the interface [25, 26], and the hydroxyl benzene propane unit decreased [27]. Water vapor and carbon dioxide were the primary components of the volatile gas in the welding process [28-30]. The wood dowel welding joints showed improved pullout resistance [31, 32]. The pullout resistance property of the wood dowel welding joints is equivalent to that of wood dowel joints with adhesives, and better than that of nailed joints [33]. Wood dowel welding may also be used to enhance the mortise and tenon interference fit connection [34]. Novel full-scale multi-layered timber beams with welded-through wood dowels obtained considerable bending strength [35].

Citric acid was used as waterproofing additive in butt joints linear wood welding [36]. In the preliminary study of wood dowel welding, wood dowels pretreated with acid solution were considered. Several preliminary tests with dowels immersed in different acid solution including $\mathrm{CuCl}_{2}, \mathrm{FeCl}_{3}, \mathrm{HCl}$ solution, and chemical copper plating were carried out. The effect of immersion time of 1, 3, 5, and 7 days was tested. According to the test results, dowels immersed in $\mathrm{CuCl}_{2}$ solution for 7 days showed the best pullout resistance. $\mathrm{CuCl}_{2}$ solution is slightly acidic because of the hydrolysis of $\mathrm{Cu}^{2+}$. The softened surface of the wood dowels caused by the acid corrosion promoted the formation of molten materials. This study aimed to analyze the influence of wood dowels immersed in $\mathrm{CuCl}_{2}$ solution for 7 days on welding performance. The chemical changes were detected using X-ray Photoelectron Spectroscopy (XPS), and Thermogravimetric (TG) analyses. These results revealed significant changes of functional groups and wood components [33, 37, 38].

\section{Materials and methods}

\section{Materials}

Wood dowels were made of birch (Betula spp.), and were $12 \mathrm{~mm}$ in diameter and $100 \mathrm{~mm}$ in length. Dowels were pre-conditioned at $336.15 \mathrm{~K}$ to obtain a $2 \%$ moisture content. The temperature of $336.15 \mathrm{~K}$ was determined from preliminary experiments because the wood dowels could achieve the desired moisture content (MC) over 2 days almost without warping and cracking. Wood dowels with a $2 \%$ moisture content were divided into two categories including a control group without pretreatment (group A) and a pretreatment group (group B). Thirty wood dowels of 
Group B were immersed in $0.1 \mathrm{~mol} / \mathrm{L} \mathrm{CuCl}$ solution with the volume of $500 \mathrm{ml}$ for 7 days at $293.15 \mathrm{~K}$ and $60 \%$ relative humidity (RH). During this immersing process, wood dowels and solution were stirred every $12 \mathrm{~h}$. After 7 days wood dowels were dried to $2 \%$ moisture content for wood dowel welding.

Larch (Larix gmelinii) slats that were $40 \mathrm{~mm}$ (Tangential, T) $\times 60 \mathrm{~mm}$ (Radial, R) $\times 1000 \mathrm{~mm}$ (Longitudinal, L) were used as the substrate. Slats were pre-conditioned at $293.15 \mathrm{~K}$ and $60 \% \mathrm{RH}$, until equilibrium moisture content was achieved.

\section{Manufacturer of specimen}

Wood substrates were pre-drilled with holes $8.5 \mathrm{~mm}$ in diameter using a drilling machine (Proxxon TBH Typ 28 124). Next, the wood dowels were welded into the predrilled holes in the substrates $30 \mathrm{~mm}$ to create bonded joints with a high-speed rotation at $1000 \mathrm{rpm}$. The insert part of the dowel was transferred to a conical shape (Fig. 1) because of the different abrasion level during the welding progress. The rotation of the wood dowel stopped when the fusion and bonding was achieved in approximately 2-4 s [4]. After welding, wood slats were cut into 10 parts evenly in the length direction so that every welded dowel was $40 \mathrm{~mm}(\mathrm{~T}) \times 60 \mathrm{~mm}(\mathrm{R}) \times 100 \mathrm{~mm}(\mathrm{~L})$ in size. The specimens were conditioned at $293.15 \mathrm{~K}$ and $60 \% \mathrm{RH}$ for 7 days before the tests were conducted.

\section{Pullout test}

The pullout resistance of the specimens was tested using universal testing equipment (WDW-300E) that pulled the welding wood dowels out of the substrate at a speed of $2 \mathrm{~mm} / \mathrm{min}$ [11]. The specimens were fixed by clamping the

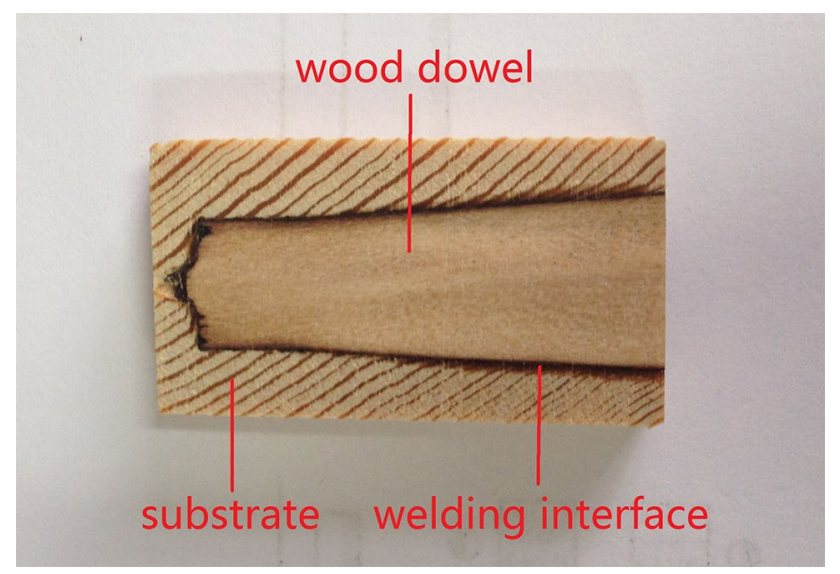

Fig. 1 The conical shape of the welding interface dowel into the jaw of the fixed beam and the substrate block was fixed to the mobile beam with a metal framework.

\section{SEM}

The samples of welding interface were conditioned to oven dry. The size of the samples was $2 \mathrm{~mm}(\mathrm{~T}) \times 2 \mathrm{~mm}$ $(\mathrm{R}) \times 10 \mathrm{~mm}(\mathrm{~L})$. The welding interface showed inhomogeneous distribution for all the specimens of group A. So the samples of group A were selected from the insufficiency and agglomerate regions. While for group B, the welding interface showed homogeneous distribution. So the samples of group B were selected from the welding interface randomly. Scanning electron microscopy (SEM) micrographs of the surfaces were obtained after metallizing with gold-palladium by a Hitachi S-3400N II microscope [14].

\section{XPS}

XPS was used to analyze the surface elements of the untreated wood dowel, wood dowel immersed in $\mathrm{CuCl}_{2}$, welding interface, and welding interface using the $\mathrm{CuCl}_{2}$ immersed dowel. Three samples which exhibited average pullout resistance with the mechanical test for each group were selected from the relative 30 specimens. The sample of wood dowel and welding interface were from the same specimen and the $\mathrm{CuCl}_{2}$ immersed wood dowel and welding interface similarly were from the same specimen. The surface samples of the untreated and treated wood dowels were cut transversally from the non-welded part of the wood dowels and the surface samples of the welding interfaces were cut from the welded part of the wood dowels. XPS analyses obtained with a spectrometer (ESCALAB 250Xi Thermo Fisher) were used to provide quantitative data to verify the elementary composition of the sample surfaces. The angle of the emitted photoelectrons was $30^{\circ}$ to the surface normal, the source type was Al K Alpha, and the analyser mode was a pass energy $100.0 \mathrm{eV}$ with an energy step size of $1.000 \mathrm{eV}$ and a total number of energy steps of 1361. The binding energy scale was corrected with reference to the $284.6 \mathrm{eV} \mathrm{C}-\mathrm{C}$ bond and a XPSpeck 41 was applied for the curve-fitting of the C1s spectra [37].

\section{TG}

Four samples were prepared for the TG test including the untreated wood dowel, wood dowel after immersion in $\mathrm{CuCl}_{2}$, the welding interface, and the welding interface produced with the dowel treated with immersion in $\mathrm{CuCl}_{2}$. Each sample was prepared by scraping and mixing the powders from the surface of the 30 tested specimens. Especially for welding interface, the powders were collected by scraping the black welding materials. All the powders of 
each sample were stirred and blended uniformly. And then the powders were dried to $0 \%$ moisture content in $373.15 \mathrm{~K}$ before TG test $[25,28]$. The TG analyses were performed using $10 \mathrm{mg}$ powders for each test. The programmed heating pyrolysis of wood dowel and welding interface was carried out in a NETZSCH STA 449F3 simultaneous thermal analyzer. The samples in the crucible of TG were heated from 323 to $973 \mathrm{~K}$ at a heating rate of $10 \mathrm{~K} \mathrm{~min}^{-1}$. The purified nitrogen was used as carrier gas to provide an inert atmosphere $[39,40]$.

\section{Results and discussion}

30 replicate welding specimens were tested for each group. The pullout resistance results are summarized in Table 1. The mean values of the welding samples using untreated wood dowels, group A, and the samples with treated wood dowels, group B, were 4027 and $4988 \mathrm{~N}$, respectively.

\section{Surface morphology of the welding interface}

From the pullout resistance test, no matter group A and B, dowels of all specimens were pulled out along the welding interface without wood fracture. All the 30 replicate welding specimens of group A showed the same surface morphology. The end 3-5 $\mathrm{mm}$ region of the wood dowels appeared blank regions (Fig. 2a) primarily because of the decreased diameter of the end region caused by the excessive friction generated during initial insertion. For the 230 replicate specimens of group B, 25 specimens showed performance as illustrated in Fig. 2b, with homogenous distribution of the molten polymer on the interface. The other 5 specimens appeared more like the untreated samples as shown in Fig. 2a.

The properties of the surface of the welding interface were observed and analyzed by SEM. The welding interface materials of group A showed inferior fluidity, leading to incompletely covered interweaved fibers (Fig. 2c) resulting in insufficiency (Fig. 2d) and agglomerate regions (Fig. 2e). Figure $2 \mathrm{f}$ showed the SEM results of the materials at the interface between the substrate hole and the wood

Table 1 Results of the pullout resistance of $30 \mathrm{~mm}$ depth predrilled holes in a single substrate

\begin{tabular}{llr}
\hline Test group & A & B \\
\hline Mean value $(N)$ & 4027 & 4988 \\
Minimum value $(N)$ & 2351 & 3855 \\
Maximum value $(N)$ & 5307 & 6301 \\
Standard deviation $(N)$ & 641 & 748 \\
\hline
\end{tabular}

Group A meant the untreated group; group B meant the treated group dowel of group B. The interface materials were well distributed. This phenomenon indicated that the molten polymer flowed along the welding interface with good fluidity during the welding process.

As seen from Fig. $2 \mathrm{~g}$, the interweaved fibers formed a skeleton structure in the welding interface. Then, the molten polymer, such as the lignin, covered the interweaved fibers to form an integrated connection between the wood dowel and substrate with considerable strength [4].

\section{XPS analyses}

The XPS analyses of wood dowel and welding interface was performed because the materials of the welding interface were mostly generated from the wood dowel [10]. During the XPS test, $\mathrm{Cu}$ and $\mathrm{Cl}$ were not identified, because few of them existed in the samples. So in the XPS test, the element of $\mathrm{C}, \mathrm{O}$, and $\mathrm{N}$ were detected. But according to the pyrolysis-gas chromatography-mass spectrometry (PY-GCMS) test, little amount of $\mathrm{Cl}$ existed in the treated wood dowel and welding interface. The content of elements and the oxygen/carbon $(\mathrm{O} / \mathrm{C})$ ratio for the wood dowels and the welding interface were shown in Table 2. The quantitative analyses were performed by peak fitting for the $\mathrm{C} 1 \mathrm{~s}$ categories. Deconvolution for the four types of carbon bonds was performed (Table 2) for the peaks from the wood dowel and welding interface and were determined as $\mathrm{C} 1$ class $(\mathrm{C}-\mathrm{C} / \mathrm{C}-\mathrm{H}$ bonds, $284.6 \mathrm{eV}), \mathrm{C} 2$ class $(\mathrm{C}-\mathrm{O}$ bonds, $286.5 \mathrm{eV}), \mathrm{C} 3$ class $(\mathrm{C}=\mathrm{O} / \mathrm{O}-\mathrm{C}-\mathrm{O}$ bonds, $287.9 \mathrm{eV})$ and $\mathrm{C} 4$ class $(\mathrm{O}=\mathrm{C}-\mathrm{O}$ bonds, $289.2 \mathrm{eV}$ ) [25].

Factor A with two levels was defined as untreatment and treatment. Factor B with two levels was defined as wood dowel and welding interface. To analyze the statistical significance of the two factors, the analysis of variance was carried out. No significant two factor interactions existed between the two factors. So in the analysis of variance, no interaction statistical significance test was done. For the results of the elements of $\mathrm{C}$, and $\mathrm{O}$, the ratio of $\mathrm{O} / \mathrm{C}, \mathrm{C} 3$, and $\mathrm{C} 4$, the factor $\mathrm{B}$ showed the high significant difference. For the results of $\mathrm{C} 1$, and $\mathrm{C} 2$, both the factor $\mathrm{A}$ and $\mathrm{B}$ showed the high significant difference. All the test results meet the requirements of homogeneity of variance. So the mean values were used to be analyzed below.

\section{Treated wood dowel vs. untreated wood dowel}

A $7.17 \%$ increase in the $\mathrm{O} / \mathrm{C}$ ratio was identified for the treated wood dowels versus the untreated wood dowels (Table 2) because the cellulose and hemicellulose were hydrolyzed in the acid solution due to the $\mathrm{CuCl}_{2}$ and the rupture of the glycosidic bond. During hydrolysis, the long chain of cellulose was broken into short ones due to chain scission and the hydrolysis of the compounds for 
hemicellulose resulted in the formation of hexose and pentose [41]. The same phenomenon was found in the PY-GCMS test, deacetylate occurred during the immersing process. According to these reactions, the portion of $\mathrm{C} 1$ and C3 decreased 5.66 and $18.26 \%$, respectively, and the portion of $\mathrm{C} 2$ increased $21.52 \%$.

\section{Wood dowel vs. welding interface for both treated and untreated samples}

Variation of $\mathrm{O} / \mathrm{C}$ indicated that the main reactions occurred during the wood welding process between the welding interface and the wood dowels. From Table 2, a 35.29 and $28.94 \%$ increase in the $\mathrm{O} / \mathrm{C}$ ratio were identified and calculated for the welding interface versus the wood dowels of group A and group B, respectively. During the rotation welding, high pressure assured the wood dowel would weld into the substrate hole quickly and successfully. Molten polymer that was rich in oxygen-containing groups formed from the amorphous cellulose, hemicellulose, and lignin that were depolymerized with the rapidly increasing temperature $[42,43]$. Because of the high speed of rotation, these polymers were mixed well together. Once the welding process stopped, the molten polymer solidified. The new generated chemical materials with oxygen-containing groups caused the $\mathrm{O} / \mathrm{C}$ increase [28].

The variation of $\mathrm{C} 1$ to $\mathrm{C} 4$ was primarily due to the depolymerization of the wood components, hydrolysis under acidic conditions and pyrolysis during the welding process. In general, the proportion of the $\mathrm{C} 1$ and $\mathrm{C} 4$ categories decreased and the proportion of the $\mathrm{C} 2$ and $\mathrm{C} 3$ increased in the welding interface versus the wood dowel.

The chemical bound water was dehydrated with a small quantity of the long cellulose broken chain for the temperature range from 420 to $510 \mathrm{~K}$ [34], which resulted in the increase of C3 [41]. Meanwhile, the pyrolysis of cellulose was observed by the Fourier Transform Infrared Spectroscopy (FTIR) analyses, which caused the decrease of $\mathrm{C} 1$. The presence of the peak at $1420 \mathrm{~cm}^{-1}$ represented the $\mathrm{CH}_{2}$ bending band of cellulose. For the treated welding interface, the intensity of the $1420 \mathrm{~cm}^{-1}$ peak decreased by the pyrolysis of cellulose fragments. For the pyrolysis of hemicellulose, furfural and other compounds were generated during the process, which resulted in the increase of $\mathrm{C} 2$, $\mathrm{C} 3$, and the decrease of $\mathrm{C} 1$. The formation of free formaldehyde from side chain scission and oxidation in the welding interface may result in the decrease in C1 [37]. Free phenolic hydroxyl groups were formed from ruptured ether bonds that caused the increase in $\mathrm{C} 2$, as observed in the $1230 \mathrm{~cm}^{-1}$ band by FTIR. The increase in $\mathrm{C} 3$ indicated that oxidation products were formed during the welding process and the heat treatment process.
Treated welding interface vs. untreated welding interface

There were differences in the $\mathrm{C} 1-\mathrm{C} 3$ data for the untreated (group A) and treated (group B) wood dowels and welding interfaces. For group $\mathrm{A}$, the portion of $\mathrm{C} 1$ decreased $12.91 \%$ and the portion of $\mathrm{C} 2$ and $\mathrm{C} 3$ increased 24.07 and $50.75 \%$, respectively. For group $\mathrm{B}$, the portion of $\mathrm{C} 1$ decreased $20.82 \%$ and the portion of $\mathrm{C} 2$ and $\mathrm{C} 3$ increased 30.34 and $77.29 \%$, respectively. From the data analyses, difference existed in the rotation welding process. Similar reactions occurred in the welding interface during the rotation welding process, but the portions of C1-C3 of wood dowel and wood dowel immersed in $\mathrm{CuCl}_{2}$ were different. So the untreated and treated welding interfaces differed in the degree and rate of pyrolysis reactions. More wood components in the treated welding interface were pyrolyzed to form furfural and other compounds during welding, causing a bigger increase of $\mathrm{C} 2$ and decrease of $\mathrm{C} 1$ and $\mathrm{C} 3$.

\section{TG/Derivative thermogravimetric analyses}

\section{TG analyses}

From the TG curves in Fig. 3a, the pyrolysis course of the welding interface was similar to that of wood dowel except for the final weight loss, which was lower for the welding interface. This phenomenon could be caused by the pyrolysis of cellulose and hemicellulose during the welding process, resulting in a higher relative content of lignin in welding interface than in the wood dowel. Based on this, the welding interface produced more coke than wood dowel during the TG testing process.

At the same time, the influence of immersion was studied. The TG curves were different in the temperature range of 500-650 K for the untreated and treated wood dowels. The weight loss rate of the treated wood dowel was higher than the untreated wood dowel. The hydrolysis of cellulose and hemicellulose in acid solution promoted the breaking of long chains and the formation of polysaccharide. The products from these changes may be more easily pyrolyzed. The final weight loss of the treated welding interface was slightly higher than the untreated welding interface. The pyrolysis and molten of lignin may be the principal factor, especially the pyrolysis of the aromatic ring [44]. This phenomenon was verified by FTIR analyses, peaks at 1508 and $1595 \mathrm{~cm}^{-1}$ represent the aromatic ring skeleton, which showed different changes for the untreated and treated welding interfaces. For untreated welding interface, the intensity of the two peaks increased due to the thermal condensation of the lignin, with the peak of $1460 \mathrm{~cm}^{-1}$ corresponding to the formation of $\mathrm{CH}_{2}$ bridges between lignin fragments [37]. For treated welding interface, the pyrolysis of aromatic ring skeleton was identified 

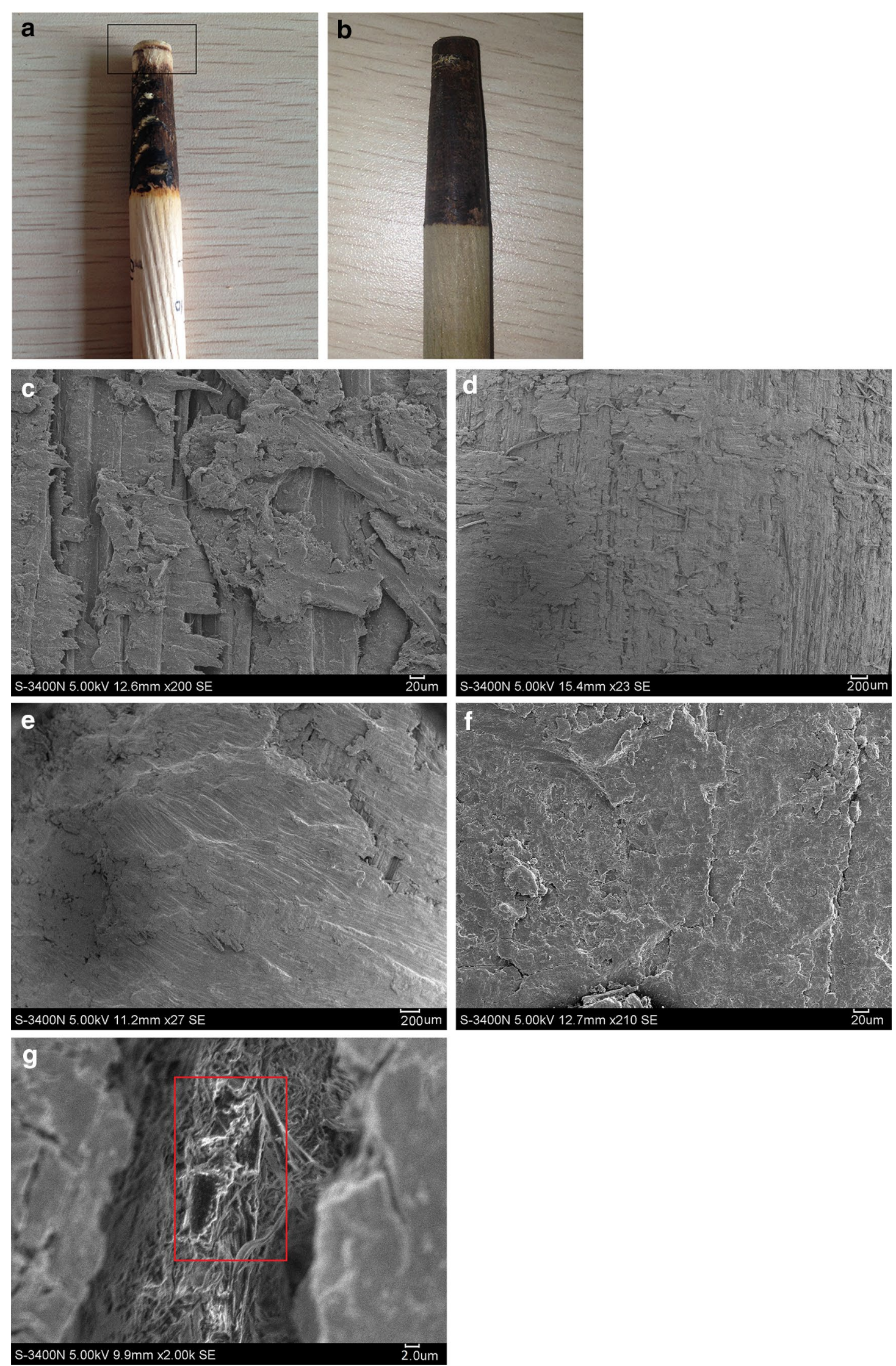
4Fig. 2 Surface morphology of the welding interface: a blank regions in the end 3-5 $\mathrm{mm}$ region, $\mathbf{b}$ homogenous distribution of the molten polymer, $\mathbf{c}$ incompletely covered interweaved fibers, $\mathbf{d}$ insufficiency regions, e agglomerate regions, $\mathbf{f}$ the interface materials well distributed, $\mathbf{g}$ a skeleton structure in the welding interface

after the welding process with the decrease of the peaks at 1508 and $1595 \mathrm{~cm}^{-1}$. According to these analyses, it could be inferred that the fluidity of lignin from the treated welding interface was better than the untreated welding interface. Because of the better fluidity, the pullout resistance of the treated welding interface was higher than that of the untreated welding interface.

\section{Derivative thermogravimetric analyses}

The pyrolysis of cellulose and hemicellulose during welding process was revealed by the Derivative thermogravimetric analyses (DTG) curves (Fig. 3b). The pyrolysis rate of the welding interface was obviously lower than that of wood dowel in the temperature range of 500-600 K. This may be due to the pyrolysis of hemicellulose during the welding process. Additionally, the pyrolysis rate of the welding interface was lower than that of the wood dowel around $635 \mathrm{~K}$ likely due to the pyrolysis of cellulose during the welding process.

As a consideration of hydrolysis, the DTG curves of untreated and treated samples showed significant differences. The curves for the treated and untreated wood dowels differed in the temperature range of 500-650 K. Similar to the TG analyses, the hydrolysis of cellulose and hemicellulose likely caused these differences. The curves of welding interfaces showed differences in the temperature of fastest pyrolysis rate: $635 \mathrm{~K}$ for the untreated and $590 \mathrm{~K}$ for the treated one. The hydrolysis of cellulose and hemicellulose occurred during immersing. Long chains of cellulose were broken into short chains, and hemicellulose was decomposed into polysaccharide. The products from these two reactions were thermal decomposed more easily than the materials of welding interface [45]. The same phenomenon was found in the PY-GC-MS test, low molecular compounds and glucose of treated samples were generated more quickly than that of untreated samples. Thus, the temperature of fastest pyrolysis rate was different for the two kinds of welding interfaces.

\section{Conclusions}

Rotation welding enabled jointing between dowels and substrate with considerable strength. The dowels that were treated by immersion in a $\mathrm{CuCl}_{2}$ solution showed improved welding properties compared with the untreated dowels. The end region of the wood dowels from the non-treatment group was not welded, but for the pretreatment group, the molten polymer on the interface was homogeneously distributed. XPS analyses showed that the hydrolysis of cellulose and hemicellulose occurred during the $\mathrm{CuCl}_{2}$ immersion process, resulting in an increase in $\mathrm{C} 2$ and a decrease in $\mathrm{C} 1$. Heat degradation of wood components occurred during the welding process, resulting in an increase in $\mathrm{C} 2$ and C3 and a decrease in C1. The hydrolysis of cellulose and hemicellulose could promote the pyrolysis and molten of wood components. From TG/DTG analyses, the pyrolysis

Table 2 Surface composition of the wood dowel and welding interface determined by XPS

\begin{tabular}{|c|c|c|c|c|c|}
\hline \multirow[t]{2}{*}{ Test group } & \multirow[t]{2}{*}{ Samples } & \multicolumn{3}{|l|}{ Elements $(\%)$} & \multirow{2}{*}{$\begin{array}{l}\text { Ratio (\%) } \\
\mathrm{O} / \mathrm{C}\end{array}$} \\
\hline & & $\mathrm{C}$ & $\mathrm{O}$ & $\mathrm{N}$ & \\
\hline \multirow[t]{2}{*}{ Group A } & Wood dowel & $76.52(1.24)$ & $22.92(1.30)$ & $0.56(0.07)$ & $29.98(2.19)$ \\
\hline & Welding interface & $70.79(1.58)$ & $28.69(1.37)$ & $0.52(0.22)$ & $40.56(2.83)$ \\
\hline \multirow[t]{2}{*}{ Group B $\left(\mathrm{CuCl}_{2}\right)$} & Wood dowel & $75.31(2.75)$ & $24.11(2.82)$ & $0.58(0.17)$ & $32.13(4.95)$ \\
\hline & Welding interface & $70.43(3.07)$ & $29.05(3.11)$ & $0.52(0.04)$ & $41.43(6.21)$ \\
\hline \multirow[t]{2}{*}{ Test group } & \multirow[t]{2}{*}{ Samples } & \multicolumn{4}{|c|}{ Carbon $\mathrm{C} 1$ s components (\%) } \\
\hline & & $\mathrm{C} 1$ & $\mathrm{C} 2$ & C3 & $\mathrm{C} 4$ \\
\hline \multirow[t]{2}{*}{ Group A } & Wood dowel & $65.23(2.97)$ & $25.14(2.80)$ & $6.68(1.87)$ & $2.95(1.69)$ \\
\hline & Welding interface & $56.81(5.02)$ & $31.19(6.19)$ & $10.07(2.26)$ & $1.93(1.81)$ \\
\hline \multirow[t]{2}{*}{ Group B $\left(\mathrm{CuCl}_{2}\right)$} & Wood dowel & $61.54(2.12)$ & $30.55(3.88)$ & $5.46(2.50)$ & $2.45(1.54)$ \\
\hline & Welding interface & $48.73(3.14)$ & $39.82(4.36)$ & $9.68(2.20)$ & $1.77(1.02)$ \\
\hline
\end{tabular}

1, wood dowel and welding interface of group A meant untreated samples; 2, wood dowel and welding interface of group B $\left(\mathrm{CuCl}_{2}\right)$ meant treated samples; 3, elements $(\%)$ of $\mathrm{C}, \mathrm{O}$, and $\mathrm{N}$ meant the amount of these elements in the samples, respectively; 4, C1: C-C/C-H bonds, $284.6 \mathrm{eV}$; $\mathrm{C} 2$ : $\mathrm{C}-\mathrm{O}$ bonds, $286.5 \mathrm{eV}$; $\mathrm{C} 3: \mathrm{C}=\mathrm{O} / \mathrm{O}-\mathrm{C}-\mathrm{O}$ bonds, $287.9 \mathrm{eV} ; \mathrm{C} 4: \mathrm{O}=\mathrm{C}-\mathrm{O}$ bonds, $289.2 \mathrm{eV} ; 5$, the ratio of $\mathrm{O} / \mathrm{C}$ meant the ratio of the amount of $\mathrm{O}$ and $\mathrm{C} ; 6$, test results were the mean value of three samples; 7 , values in parentheses were standard deviation 

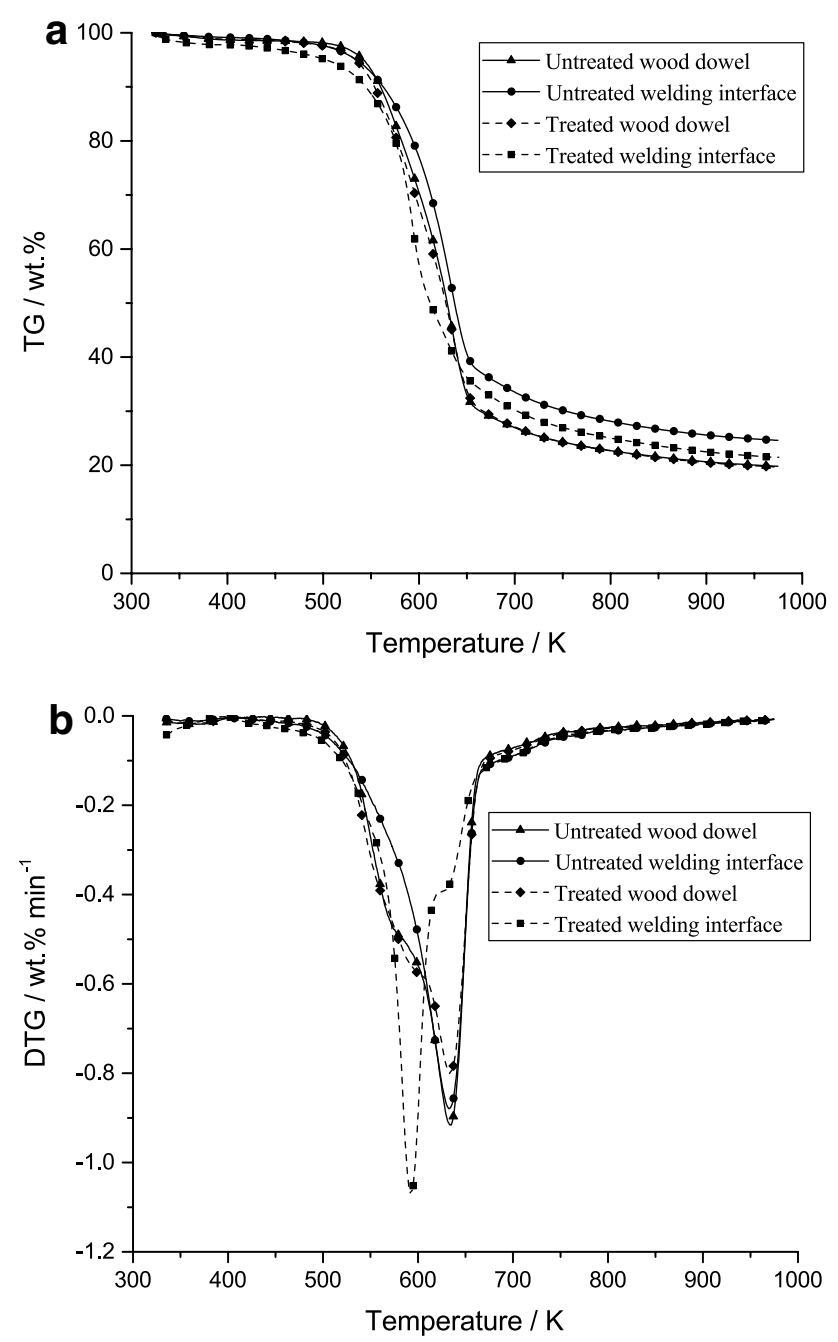

Fig. 3 The TG and DTG graphs of the treated and untreated wood dowels and welding interfaces: a TG, b DTG

degree of hemicellulose was higher than that of cellulose and lignin. The hydrolysis of cellulose and hemicellulose occurred during immersion and hydrolysis reduced the pyrolysis temperature of cellulose and hemicellulose.

Acknowledgements This research work was jointly supported by the BMCE Science Research and Graduate Student Construction Projects: Properties and Application Research of Outdoor Wood Architecture Material (2015GJ-01), and the project for Follow-up Hot Issues of Beijing Forestry University (2016BLRD03).

Author contributions Ying Gao and Songlin Yi designed the experiment, Xudong Zhu and Chun Ni performed the experiment and analyzed data; Jirong Zhang and Xiangya Luo completed pullout resistance test; Xudong Zhu prepared and edited the manuscript, and Ying Gao reviewed and directed the manuscript.

\section{Compliance with ethical standards}

Conflict of interest The authors declare no conflict of interest.

\section{References}

1. Ganne-Chedeville C, Pizzi A, Thomas A, Leban JM, Bocquet JF, Despres A, Mansouri H (2005) Parameter interactions in twoblock welding and the wood nail concept in wood dowel welding. J Adhes Sci Technol 19:1157-1174

2. Zhou XJ, Pizzi A, Du GB (2014) Research progress of wood welding technology (bonding without adhesive). China Adhesives 23: 47-53

3. Sandberg D, Haller P, Navi P (2013) Thermo-hydro and thermos-hydro-mechanical wood processing: an opportunity for future environmentally friendly wood products. Wood Mater Sci Eng 8:64-88

4. Ganne-Chedeville C, Properzi M, Leban JM, Pizzi A, Pichelin F (2008) Wood welding chemical and physical changes according to the welding time. J Adhes Sci Technol 22:761-773

5. Stamm B, Natterer J, Navi P (2005) Joining of wood layers by friction welding. J Adhes Sci Technol 19:1129-1139

6. Stamm B, Natterer J, Navi P (2005) Joining wood by friction welding. Holz Roh Werkst 63:313-320

7. Stamm B, Weinand Y, Hahn B, Rossmaier G (2011) Influence of the moisture content on the shear strength of welded woodto-wood connections. In: COSTWorkshop Mechano-chemical transformations of wood during THM processing, pp 131-133

8. Zoulalian A, Pizzi A (2007) Wood-dowel rotation welding-a heat-transfer mode. J Adhes Sci Technol 21:97-108

9. Mansouri HR, Pizzi A, Leban JM, Delmotte L, Lindgren O, Vaziri M (2011) Causes for the improved water resistance in Pine wood linear welded joints. J Adhes Sci Technol 25:1987-1995

10. Belleville B, Stevanovic T, Pizzi A, Cloutier A, Blanchet P (2013) Determination of optimal wood welding parameters for two North American hardwood species. J Adhes Sci Technol 27:566-576

11. Kanazawa F, Pizzi A, Properzi M, Delmotte L, Pichelin F (2005) Parameters influencing wood-dowel welding by high-speed rotation. J Adhes Sci Technol 19:1025-1038

12. Leban JM, Mansouri HR, Omrani P, Pizzi A (2008) Dependence of dowel welding on rotation rate. Holz Roh Werkst 66:241-242

13. Auchet S, Segovia C, Mansouri HR, Meausoone PJ, Pizzi A, Omrani P (2010) Accelerating vs constant rate of insertion in wood dowel welding. J Adhes Sci Technol 24:1319-1328

14. Rodriguez G, Diouf P, Blanchet P, Stevanovic T (2010) Wooddowel bonding by high-speed rotation welding-application to two Canadian hardwood species. J Adhes Sci Technol 24:1423-1436

15. Pizzi A, Leban JM, Kanazawa F, Properzi M, Pichelin F (2004) Wood dowel bonding by high-speed rotation welding. J Adhes Sci Technol 18:1263-1278

16. Belleville B, Segovia C, Pizzi A, Stevanovic T, Cloutier A (2011) Wood blockboards fabricated by rotational dowel welding. J Adhes Sci Technol 25:2745-2753

17. Bocquet FJ, Pizzi A, Despres A, Mansouri HR, Resch L, Michel D, Letort F (2007) Wood joints and laminated wood beams assembled by mechanically-welded wood dowels. J Adhes Sci Technol 21:301-317

18. Mansouri HR, Pizzi A, Leban JM, Delmotte L, Lindgren O, Vaziri M (2011) Causes of the characteristic improved water resistance in pine wood linear welding. J Adhes Sci Technol 25:1987-1995

19. Pizzi A, Zhou X, Navarrete P, Segovia C, Mansouri HR, Placentia PMI, Pichelin F (2012) Enhancing water resistance of welded dowel wood joints by acetylated lignin. J Adhes Sci Technol $1: 1-11$

20. Ganier T, Hu J, Pizzi A (2013) Causes of the water resistance of welded joints of Paduk wood (Pterocarpus soyauxii, Taub.). J Renew Resour 1:79-82 
21. Placencia PMI, Rheme M, Pizzi A, Pichelin F (2015) Mechanical properties of welded wood joints with natural additives. Holztechnologie 56: 5-9

22. Pizzi A, Mansouri HR, Leban JM, Delmotte L, Omrani P, Pichelin F (2011) Enhancing the exterior performance of wood linear and rotational welding. J Adhes Sci Technol 25:2717-2730

23. Placencia PMI, Deutschle AL, Saake B, Pizzi A, Pichelin F (2015) Study of the solubility and composition of welded wood material at progressive welding times. Eur J Wood Prod 74: 191-201

24. Karl-Christian M, Stergios A, Gerald K, Holger M (2013) Topochemistry of heat-treated and N-methylol melamine-modified wood of koto (Pterygota macrocarpa K. Schum.) and limba (Terminalia superba Engl. et Diels). Holzforschung 67:137-146

25. Sun Y, Royer M, Diouf PN, Stevanovic T (2010) Chemical changes induced by high-speed rotation welding of wood-application to two Canadian hardwood species. J Adhes Sci Technol 24:1383-1400

26. Delmotte L, Mansouri HR, Omeani P, Pizzi A (2009) Influence of wood welding frequency on wood constituents chemical modifications. J Adhes Sci Technol 23:1271-1279

27. Omrani P, Masson E, Pizzi A, Mansouri HR (2008) Emission of gases and degradation volatiles from polymeric wood constituents in friction welding of wood dowels. Polym Degrad Stabil 93:794-799

28. Stamm B, Windeisen E, Natterer J, Wegener G (2006) Chemical investigations on the thermal behaviour of wood during friction welding. Wood Sci Technol 40:615-627

29. Omrani P, Masson E, Pizzi A, Mansouri HR (2008) Emission gasses and degradation volatiles from polymeric wood constituents in wood dowels friction welding. Polymer Degrad Stab 93:794-799

30. Omrani P, Masson E, Pizzi A, Mansouri HR (2009) Emission gasses in linear vibration welding of wood. J Adhes Sci Technol 23:85-94

31. Omrani P, Bocquet JF, Pizzi A, Leban JM, Mansouri H (2007) Zig-zag rotational dowel welding for exterior wood joints. J Adhes Sci Technol 21:923-933

32. Resch L, Despres A, Pizzi A, Bocquet JF, Leban JM (2006) Welding-through doweling of wood panels. Holz als Roh-und Werkstoff 64:423-425

33. Segovia C, Pizzi A (2009) Performance of dowel-welded wood furniture linear joints. J Adhes Sci Technol 23:1293-1301
34. Mougel E, Segovia C, Pizzi A, Thoman A (2011) Shrink-fitting and dowel welding in mortise and tenon structural wood joints. J Adhes Sci Technol 25:213-221

35. Loisingh CO, Oudjene M, Adler HA, Fanning P, Pizzi A, Shotton E, Meghlat EM (2012) Experimental study of timber-to-timber composite beam using welded-through wood dowels. Construct Build Mat 36:245-250

36. Amirou S, Pizzi A, Delmotte L (2017) Citric acid as waterproofong additive in butt joints linear wood welding. Eur J Wood Wood Prods. doi:10.1007/s00107-017-1167-x

37. Belleville B, Stevanovic T, Cloutier A, Pizzi A, Prado M, Erakovic S, Diouf PN, Royer M (2013) An investigation of thermochemical changes in Canadian hardwood species during wood welding. Eur J Wood Prod 71:245-257

38. Delmotte L, Ganne-Chedeville C, Leban JM, Pizzi A, Pichelin F (2007) CP-MAS 13 C NMR and FT-IR investigation of the degradation reactions of polymer constituents in wood welding. Polym Degrad Stabil 93:406-412

39. Tan H, Wang SR, Luo ZY, Cen KF (2006) Pyrolysis behavior of cellulose, xylan and lignin. J Fuel Chem Technol 34:61-65

40. Hu SY, Zhang ZP, Huang BZ (1998) Analysis of DTA/TG curve of wood flame retardant of inorganic boride series. J Fujian Coll For 18:163-166

41. Pei JC, Ping QW, Tang AM (2014) Chap. 3, Sect. 7 The degradation of cellulose and Chap. 4, Sect. 7 The chemical property of hemicellulose. Lignocellulosic chemistry. China Light Industry Press, Beijing, pp 162-307

42. Dong CQ, Zhang ZF, Lu Q, Yang YP (2012) Characteristics and mechanism study of analytical fast pyrolysis of poplar wood. Energy Convers Manage 57:49-59

43. Chen WH, Kuo PC (2011) Isothermal torrefaction kinetics of hemicellulose, cellulose, lignin and xylan using thermogravimetric analysis. Energy 36:6451-6460

44. Lu Q, Yang XC, Dong CQ, Zhang ZF, Zhang XM, Zhu XF (2011) Influence of pyrolysis temperature and time on the cellulose fast pyrolysis products: analytical Py-GC/MS study. J Anal Appl Pyrol 92:430-438

45. Shi Q (2011) The mechanism and effect on the properties of heat-treated okan wood. Dissertation, Chinese Academy of Forestry, China 